\title{
Communication \\ Unexpected Metal-Free Dehydrogenation of a $\beta$-Ketoester to a
Phenol Using a Recyclable Oxoammonium Salt
}

Fabrizio Politano $(\mathbb{B}$, William P. Brydon, Jyoti Nandi $(\mathbb{D}$ and Nicholas E. Leadbeater *(i)

Citation: Politano, F.; Brydon, W.P.; Nandi, J.; Leadbeater, N.E. Unexpected Metal-Free

Dehydrogenation of a $\beta$-Ketoester to a Phenol Using a Recyclable Oxoammonium Salt. Molbank 2021, 2021, M1180. https://doi.org/ 10.3390/M1180

Academic Editors: Stefano D’Errico and Annalisa Guaragna

Received: 23 December 2020

Accepted: 7 January 2021

Published: 13 January 2021

Publisher's Note: MDPI stays neutral with regard to jurisdictional clai$\mathrm{ms}$ in published maps and institutional affiliations.

Copyright: (C) 2021 by the authors. Licensee MDPI, Basel, Switzerland. This article is an open access article distributed under the terms and conditions of the Creative Commons Attribution (CC BY) license (https:// creativecommons.org/licenses/by/ $4.0 /)$.
Department of Chemistry, University of Connecticut, 55 North Eagleville Road, Storrs, CT 06269-3060, USA; fabrizio.politano@uconn.edu (F.P.); william.brydon@uconn.edu (W.P.B.); jyoti.nandi@uconn.edu (J.N.)

* Correspondence: nicholas.leadbeater@uconn.edu

Abstract: The conversion of ethyl 2-oxocyclohexanecarboxylate to ethyl salicylate using an oxoammonium salt is reported. The dehydrogenation reaction is operationally simple and compares favorably with previous literature examples for the same transformation and expands the scope of oxoammonium salts as reagents for oxidative functionalization processes.

Keywords: oxoammonium salt; dehydrogenation; phenol; recyclable; ketone

\section{Introduction}

Oxoammonium salts are stable, metal-free oxidants that are recyclable and can be used under mild conditions. They and their nitroxide analogs have been employed extensively for the oxidation of alcohols to aldehydes, ketones, and carboxylic acids [1-7]. The most widely used oxoammonium salt is 4-acetamido-2,2,6,6-tetramethylpiperidine-1oxoammonium tetrafluoroborate, 1 (Figure 1) [7]. Moving beyond simple alcohol oxidation, $\mathbf{1}$ can also be used as a reagent for a range of oxidative functionalization reactions [8-11]. These include oxidative esterification [12], amidation [13], and the preparation of nitriles from aldehydes [14]. It is also possible to couple $\mathbf{1}$ with visible-light photocatalysis in a dual catalytic system [15-22]. When using 1 in a stoichiometric perspective, one transformation of particular interest is the dehydrogenation of ketones (Scheme 1) [23,24].
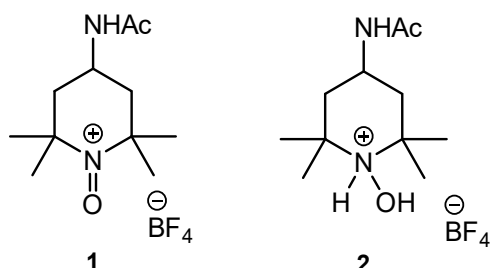<smiles>CCNC1CC(C)(C)N([O])C(C)(C)C1</smiles>

Figure 1. Oxoammonium salt $\mathbf{1}$ and its hydroxyammonium and nitroxide analogs 2, and 3.

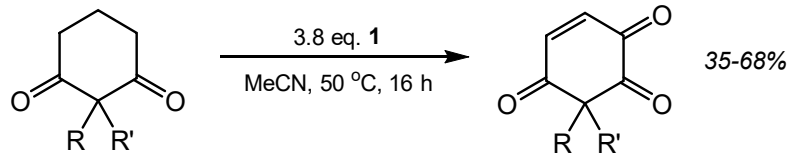

$R$ and $R^{\prime}=M e$, allyl, propargyl, cyclohexenyl

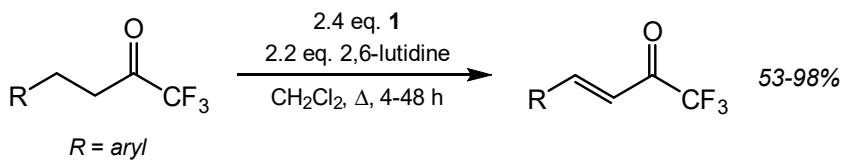

Scheme 1. Dehydrogenation of ketones using oxoammonium salt 1. 
Ene-triketones have been prepared by oxidation of diketones [25], and perfluoroalkyl ketones can be converted to their $\alpha, \beta$-unsaturated analogs [26]. Reactions are performed in the presence of a nitrogenous base such as pyridine or 2,6-dimethylpyridine (2,6-lutidine). A superstoichiometric quantity of the oxoammonium salt is required because, in the presence of a base, the hydroxyammonium byproduct, 2 , initially formed undergoes a comproportionation reaction with a further aliquot of $\mathbf{1}$ to generate two equivalents of nitroxide $\mathbf{3}[27,28]$. Thus, a sacrificial equivalent of $\mathbf{1}$ is required in order to affect complete dehydrogenation of the substrate. The spent oxidant can be easily removed by filtration at the end of a reaction and converted back to 1 [29].

In an attempt to expand the scope of previous methodologies, we sought to use $\mathbf{1}$ for the dehydrogenation of a range of cyclohexanones. This transformation is traditionally performed using hypervalent iodine reagents [30] or by palladium catalysis [31]. We wanted to see if $\mathbf{1}$ could be used as an environmentally benign alternative. As a sharpening stone for probing this reaction, our attention focused on ethyl 2-oxocyclohexanecarboxylate, 4, as a substrate. However, rather than obtaining ethyl 2-oxo-3-cyclohexene-1-carboxylate, 5 , as the product, we observed the formation of ethyl salicylate, 6, a well-known phenolic compound (Scheme 2) [32-36]. We report this serendipitous discovery here.<smiles>CCOC(=O)C1CCCCC1=O</smiles>

4

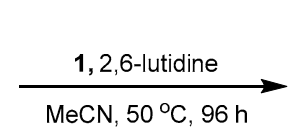

EXPECTED<smiles>CCOC(=O)C1CCC=CC1=O</smiles>

5<smiles>CCOC(=O)c1ccccc1O</smiles>

6

OBSERVED

Scheme 2. Conversion of $\beta$-ketoester 4 to phenol 6 rather than $\alpha, \beta$-unsaturated $\beta$-ketoester 5 .

\section{Results and Discussion}

Our discovery arose when we performed the reaction of 4 with 3.6 eq. of $\mathbf{1}$, using 5 eq. of 2,6-lutidine as a base. Heating an acetonitrile solution of the reagents at $50^{\circ} \mathrm{C}$ for $96 \mathrm{~h}$ led to an almost equimolar ratio of phenol $\mathbf{6}$ and unreacted starting material 4 (Table 1, entry 1). Increasing the loading of 1 to $7.5 \mathrm{eq}$. and reducing the reaction time to $24 \mathrm{~h}$, resulted in complete conversion to 6 (entry 2). Performing the reaction in absence of 2,6-lutidine was not successful, indicating the importance of the base (entry 3 ). Reducing the reaction temperature to $25^{\circ} \mathrm{C}$ slowed the reaction considerably, it taking $72 \mathrm{~h}$ to reach completion (entries 4 and 5). Operating at $50{ }^{\circ} \mathrm{C}$ but reducing the oxoammonium salt loading to 5 eq. required extending the reaction time to $72 \mathrm{~h}$ (entry 6). Attempts to perform the reaction catalytically in $\mathbf{1}$ using a number of secondary oxidants were not successful. In order to improve the efficacy of the stoichiometric protocol, we wanted to reduce the reaction time. To achieve this, we turned to using microwave heating under sealed-vessel conditions as a tool. This way we were able to reach $100{ }^{\circ} \mathrm{C}$ simply and safely and could reduce the reaction time from $24 \mathrm{~h}$ to $30 \mathrm{~min}$ and obtain a near-quantitative conversion (entry 7). These became the optimal conditions for the protocol.

Our attention turned next to the isolation of the phenol from the product mixture. With an organic base and byproducts from the oxoammonium salt in the mixture, isolation of 6 involved a series of extractions. The product mixture was first diluted with water and then dilute hydrochloric acid added. An extraction with petroleum ether removed non-acidic byproducts. The organic layer was then washed with dilute sodium hydroxide in order to extract the product as the phenoxide anion into the aqueous phase and leaving organic byproducts, spent oxidant, and any unreacted starting material in the organic phase. Acidification of the aqueous extract with dilute hydrochloric acid liberated the phenol which was then extracted using petroleum ether. Removal of the solvent gave 6 in $40 \%$ isolated yield. 
Table 1. Optimization of reaction conditions for the conversion of $\beta$-ketoester 4 to phenol $6^{\mathrm{a}}$.

\begin{tabular}{cccccc}
\hline Entry & $\mathbf{1}$ (eq.) & 2,6-Lutidine (eq.) & Temperature $\left({ }^{\circ} \mathbf{C}\right)$ & Time (h) & Conversion to $\mathbf{6}(\%) \mathbf{~}^{\mathbf{b}}$ \\
\hline 1 & 3.6 & 5 & 50 & 96 & 51 \\
2 & 7.5 & 5 & 50 & 24 & 100 \\
3 & 7.5 & 0 & 50 & 24 & 0 \\
4 & 7.5 & 5 & 25 & 72 & 53 \\
5 & 7.5 & 5 & 25 & 72 & 95 \\
6 & 5.0 & 5 & 50 & 72 & 92 \\
$7^{\mathrm{c}}$ & 7.5 & 5 & 100 & 0.5 & 100 \\
\hline
\end{tabular}

a Reagents and conditions: ethyl 2-oxocyclohexanecarboxylate $(4,0.5 \mathrm{mmol}, 1 \mathrm{eq}$.$) , acetonitrile (2 \mathrm{~mL}, 0.25 \mathrm{M}$ in 4), requisite quantity of $\mathbf{1}$ and 2,6-lutidine, stirred at the desired temperature in an oil bath for the allotted time

${ }^{\mathrm{b}}$ Determined using GCMS. ${ }^{\mathrm{c}}$ Performed using microwave heating.

The fact that phenol $\mathbf{6}$ is formed in the reaction of $\mathbf{4}$ with $\mathbf{1}$ is noteworthy in light of the two other literature reports of this transformation. One employs an $o$-iodoxybenzoic acid derivative bearing a trimethylammonium group [30]. A comparable yield of 6 is obtained in the oxidative dehydrogenation of 4 . The other approach involves the use of $10 \mathrm{~mol} \%$ of palladium chloride in conjunction with 2 eq. of chloranil as a terminal oxidant [31]. The phenol product is obtained in 95\% yield after $18 \mathrm{~h}$. Compared to these reports, our methodology has the advantage that it is metal-free and that the oxidant is cheaper, easier to use, recyclable, and non-toxic.

\section{Materials and Methods}

\subsection{General}

All microwave-heating reactions were performed using a CEM Discover SP microwave unit (CEM Corporation, Matthews, NC, USA), in closed-vessel configuration. Temperature was measured by means of an IR temperature sensor located below the reaction vessel. NMR spectra $\left({ }^{1} \mathrm{H},{ }^{13} \mathrm{C}\right)$ were obtained in deuterated chloroform at $300 \mathrm{~K}$ using a Brüker DRX-400 $400 \mathrm{MHz}$ spectrometer (Brüker, Billerica, MA, USA). ${ }^{1} \mathrm{H}-\mathrm{NMR}$ spectra were referenced to residual $\mathrm{CHCl}_{3}(7.26 \mathrm{ppm})$ in $\mathrm{CDCl}_{3} \cdot{ }^{13} \mathrm{C}-\mathrm{NMR}$ spectra were referenced to $\mathrm{CDCl}_{3}$ (77.16 ppm). Reactions were monitored by an Agilent Technologies (Santa Clara, CA, USA) 7820A Gas Chromatograph attached to a 5975 Mass Spectrometer.

\subsection{Chemicals}

Ethyl 2-oxocyclohexanecarboxylate [CAS 1655-07-8] was purchased from Acros Organics (Geel, Belgium). 2,6-lutidine [CAS 108-48-5] was purchased from Oakwood Chemical (Estill, SC, USA). Acetonitrile [CAS 75-05-8] was obtained from Sigma-Aldrich (St. Louis, MO, USA). Petroleum ether [CAS 8032-32-4] was purchased from Fisher Scientific (Hampton, $\mathrm{NH}$, USA). Deuterated chloroform $\left(\mathrm{CDCl}_{3}\right)$ [CAS 865-49-6] was purchased from Cambridge Isotope Laboratories (Tewksbury, MA, USA). Oxoammonium salt, 1, [CAS 219543-09-6] was prepared using a literature procedure [29].

\subsection{Synthesis of Ethyl Salicylate (6) [CAS 118-61-6]}

Ethyl 2-oxocyclohexanecarboxylate [CAS 1655-07-8] (4, 1 mmol, 1 eq), 2,6-lutidine [CAS 108-48-5] (5 mmol, 5 eq), 4-acetylamino-2,2,6,6-tetramethylpiperidine-1-oxoammonium tetrafluoroborate $(\mathbf{1}, 7.5 \mathrm{mmol}, 7.5 \mathrm{eq})$, acetonitrile $(3 \mathrm{~mL})$ and deionized water $(1 \mathrm{~mL})$ were added to a $40 \mathrm{~mL}$-capacity glass tube equipped with a magnetic stir bar. The reaction mixture was sealed with a cap and placed into a CEM Discover SP microwave unit. The content of the vessel was heated to $100{ }^{\circ} \mathrm{C}$ and held at this temperature for $30 \mathrm{~min}$, the microwave power automatically fluctuating to hold the reaction mixture at the desired temperature. The reaction mixture was stirred constantly. After the allotted time, the reaction mixture was allowed to cool to below $50{ }^{\circ} \mathrm{C}$ before taking the vessel out of the microwave unit. An intensely colored solution was obtained at this point. The product mixture was transferred from the glass tube to a separatory funnel whereupon water $(2 \mathrm{~mL})$ was added, followed by $1 \mathrm{M} \mathrm{HCl}(5 \mathrm{~mL})$. An extraction with petroleum ether was 
performed $(5 \times 10 \mathrm{~mL})$ in order to remove non-acidic byproducts. The organic layer was then washed with $0.5 \mathrm{M} \mathrm{NaOH}(2 \times 25 \mathrm{~mL})$ in order to extract the product in phenoxide anion form. At this point the color of the solution changed from yellow to green. The two basic aqueous fractions were collected and acidified with $2 \mathrm{M} \mathrm{HCl}$ until a $\mathrm{pH}$ of less than 3 was reached $(\sim 30 \mathrm{~mL}$ acid). At this point the solution turned a cloudy yellow color. This solution was extracted with petroleum ether $(3 \times 30 \mathrm{~mL})$. The combined organic extracts were washed with brine $(\sim 30 \mathrm{~mL})$ and dried over $\mathrm{Na}_{2} \mathrm{SO}_{4}$. The solvent was removed under reduced pressure by rotary evaporation affording pure phenol 6 as a yellow oil $(66 \mathrm{mg}$, $40 \%) .{ }^{1} \mathrm{H}-\mathrm{NMR}\left(400 \mathrm{MHz}, \mathrm{CDCl}_{3}\right): \delta \mathrm{ppm} 10.84(\mathrm{~s}, 1 \mathrm{H}), 7.85(\mathrm{dd}, J=8.0,1.8 \mathrm{~Hz}, 1 \mathrm{H})$, $7.45(\mathrm{ddd}, J=8.8,7.2,1.8 \mathrm{~Hz}, 1 \mathrm{H}), 6.98(\mathrm{dd}, J=8.4,1.1 \mathrm{~Hz}, 1 \mathrm{H}), 6.88(\mathrm{ddd}, J=8.2,7.2,1.1$ $\mathrm{Hz}, 1 \mathrm{H}), 4.41(\mathrm{q}, J=7.1 \mathrm{~Hz}, 2 \mathrm{H}), 1.42(\mathrm{t}, J=7.1 \mathrm{~Hz}, 3 \mathrm{H}) .{ }^{13} \mathrm{C}-\mathrm{NMR}\left(101 \mathrm{MHz}, \mathrm{CDCl}_{3}\right): \delta$ ppm 170.36, 161.83, 135.73, 130.05, 119.22, 117.70, 112.79, 77.48, 77.16, 76.84, 61.55, 14.33 . GC-MS: (EI), $m / z$ (relative intensity, \%), 166 ([M] $\left.]^{+}, 39\right), 121$ (28), 120 (100), 92 (37), 65 (11). Spectral data for this compound are consistent with those previously reported $[37,38]$ (Supplementary Materials).

\section{Conclusions}

In summary, we report the conversion of $\beta$-ketoester 4 to a phenol 6 using oxoammonium salt 1 . The reaction is operationally simple and compares favorably with previous literature examples for the same transformation. This serendipitous discovery opens the door to further exploration of the dehydrogenation of ketones to generate phenol products and work is currently underway in our laboratory to this end.

Supplementary Materials: The following are available online. ${ }^{1} \mathrm{H}$ - and ${ }^{13} \mathrm{C}-\mathrm{NMR}$, and GCMS spectra of product 6 .

Author Contributions: Conceptualization, N.E.L. and J.N.; methodology, W.P.B., J.N. and F.P.; data curation, W.P.B., J.N. and F.P.; writing—original draft preparation, N.E.L. and F.P.; writing-review and editing, W.P.B., N.E.L., J.N. and F.P.; supervision, N.E.L. and F.P.; project administration, N.E.L.; funding acquisition, N.E.L. All authors have read and agreed to the published version of the manuscript.

Funding: This research was funded by the University of Connecticut Research Enhancement Program and Office of Undergraduate Research.

Data Availability Statement: The data presented in this study are available in the article and Supplementary Material.

Acknowledgments: The University of Connecticut is thanked for financial support.

Conflicts of Interest: The authors declare no conflict of interest.

\section{References}

1. Shibuya, M. Nitroxyl Radical-Catalyzed Chemoselective Alcohol Oxidation for the Synthesis of Polyfunctional Molecules. Tetrahedron Lett. 2020, 61, 151515. [CrossRef]

2. Beejapur, H.A.; Zhang, Q.; Hu, K.; Zhu, L.; Wang, J.; Ye, Z. TEMPO in Chemical Transformations: From Homogeneous to Heterogeneous. ACS Catal. 2019, 9, 2777-2830. [CrossRef]

3. Tebben, L.; Studer, A. Nitroxides: Applications in synthesis and in polymer chemistry. Angew. Chem. Int. Ed. 2011, 50, 5034-5068. [CrossRef] [PubMed]

4. Ciriminna, R.; Pagliaro, M. Industrial oxidations with organocatalyst TEMPO and its derivatives. Org. Proc. Res. Dev. 2010, 14, 245-251. [CrossRef]

5. Bobbitt, J.M.; Brückner, C.; Merbouh, N. Oxoammonium-catalyzed oxidation. Org. React. 2009, 74, $103-206$.

6. Vogler, T.; Studer, A. Applications of TEMPO in Synthesis. Synthesis 2008, 1979-1993. [CrossRef]

7. Kelly, C.B. 2,2,6,6-Tetramethylpiperidine-Based Oxoammonium Salts. Synlett 2013, 24, 527-528. [CrossRef]

8. Leadbeater, N.E.; Bobbitt, J.M. TEMPO-Derived Oxoammonium Salts as Versatile Oxidizing Agents. Aldrichimica Acta 2014, $47,65-74$.

9. Gini, A.; Brandhofer, T.; Mancheño, O.G. Recent Progress in Mild Csp3-H Bond Dehydrogenative or (Mono-) Oxidative Functionalization. Org. Biomol. Chem. 2017, 15, 1294-1312. [CrossRef] 
10. Garcia-Mancheño, O.; Stopka, T. TEMPO Derivatives as Alternative Mild Oxidants in Carbon-Carbon Coupling Reactions. Synthesis 2013, 45, 1602-1611. [CrossRef]

11. Rohlmann, R.; Garcia-Mancheño, O. Metal-Free Oxidative C( $\left.\mathrm{sp}^{3}\right)$-H Bond Couplings as Valuable Synthetic Tools for C-C Bond Formations. Synlett 2013, 24, 6-10. [CrossRef]

12. Kelly, C.B.; Mercadante, M.A.; Wiles, R.J.; Leadbeater, N.E. Oxidative Esterification of Aldehydes Using a Recyclable Oxoammonium Salt. Org. Lett. 2013, 15, 2222-2225. [CrossRef] [PubMed]

13. Ovian, J.M.; Kelly, C.B.; Pistritto, V.A.; Leadbeater, N.E. Accessing N-Acyl Azoles via Oxoammonium Salt-Mediated Oxidative Amidation. Org. Lett. 2017, 19, 1286-1289. [CrossRef] [PubMed]

14. Kelly, C.B.; Lambert, K.M.; Mercadante, M.A.; Ovian, J.M.; Bailey, W.F.; Leadbeater, N.E. Access to Nitriles from Aldehydes Mediated by an Oxoammonium Salt. Angew. Chem. Int. Ed. 2015, 54, 4241-4245. [CrossRef]

15. Twilton, J.; Le, C.; Zhang, P.; Shaw, M.H.; Evans, R.W.; MacMillan, D.W.C. The merger of transition metal and photocatalysis. Nat. Rev. Chem. 2017, 1, 52. [CrossRef]

16. Shaw, M.H.; Twilton, J.; Macmillan, D.W.C. Photoredox Catalysis in Organic Chemistry. J. Org. Chem. 2016, 81, 6898-6926. [CrossRef]

17. Romero, N.A.; Nicewicz, D.A. Organic Photoredox Catalysis. Chem. Rev. 2016, 116, 10075-10166. [CrossRef]

18. Prier, C.K.; Rankic, D.A.; Macmillan, D.W.C. Visible Light Photoredox Catalysis with Transition Metal Complexes: Applications in Organic Synthesis. Chem. Rev. 2013, 113, 5322-5363. [CrossRef]

19. Nandi, J.; Vaughan, M.Z.; Sandoval, A.L.; Paolillo, J.M.; Leadbeater, N.E. Oxidative Amidation of Amines in Tandem with Transamidation: A Route to Amides Using Visible-Light Energy. J. Org. Chem. 2020, 85, 9219-9229. [CrossRef]

20. Nandi, J.; Leadbeater, N.E. Visible-light-driven catalytic oxidation of aldehydes and alcohols to nitriles by 4-acetamido-tempo using ammonium carbamate as a nitrogen source. Org. Biomol. Chem. 2019, 17, 9182-9186. [CrossRef]

21. Nandi, J.; Witko, M.L.; Leadbeater, N.E. Combining Oxoammonium Cation Mediated Oxidation and Photoredox Catalysis for the Conversion of Aldehydes into Nitriles. Synlett 2018, 29, 2185-2190.

22. Pistritto, V.A.; Paolillo, J.M.; Bisset, K.A.; Leadbeater, N.E. Oxidation of $\alpha$-trifluoromethyl and non-fluorinated alcohols via the merger of oxoammonium cations and photoredox catalysis. Org. Biomol. Chem. 2018, 16, 4715-4719. [CrossRef] [PubMed]

23. Bosque, I.; Chinchilla, R.; Gonzalez-Gomez, J.C.; Guijarro, D.; Alonso, F. Cross-Dehydrogenative Coupling Involving Benzylic and Allylic C-H Bonds. Org. Chem. Front. 2020, 7, 1717-1742. [CrossRef]

24. Bao, X.; Jiang, W.; Liang, J.; Huo, C. One-Electron Oxidative Dehydrogenative Annulation and Cyclization Reactions. Org. Chem. Front. 2020, 7, 2107-2144. [CrossRef]

25. Eddy, N.A.; Kelly, C.B.; Mercadante, M.A.; Leadbeater, N.E.; Fenteany, G. Access to dienophilic ene-triketone synthons by oxidation of diketones with an oxoammonium salt. Org. Lett. 2012, 14, 498-501. [CrossRef]

26. Hamlin, T.A.; Kelly, C.B.; Leadbeater, N.E. Dehydrogenation of Perfluoroalkyl Ketones Using a Recyclable Oxoammonium Salt. Eur. J. Org. Chem. 2013, 3658-3661. [CrossRef]

27. Hamlin, T.A.; Kelly, C.B.; Ovian, J.M.; Wiles, R.J.; Tilley, L.J.; Leadbeater, N.E. Toward a Unified Mechanism for Oxoammonium Salt-Mediated Oxidation Reactions: A Theoretical and Experimental Study Using a Hydride Transfer Model. J. Org. Chem. 2015, 80, 8150-8167. [CrossRef]

28. Bobbitt, J.M.; Bartelson, A.L.; Bailey, W.F.; Hamlin, T.A.; Kelly, C.B. Oxoammonium Salt Oxidations of Alcohols in the Presence of Pyridine Bases. J. Org. Chem. 2014, 79, 1055-1067. [CrossRef]

29. Mercadante, M.; Kelly, C.B.; Bobbitt, J.M.; Tilley, L.J.; Leadbeater, N.E. Synthesis of 4-acetamido-2,2,6,6-tetramethylpiperidine-1oxoammonium tetrafluoroborate and 4-acetamido-(2,2,6,6-tetramethyl-piperidin-1-yl)oxyl and their use in oxidative reactions. Nat. Protoc. 2013, 8, 666-676. [CrossRef]

30. Cui, L.Q.; Dong, Z.L.; Liu, K.; Zhang, C. Design, Synthesis, Structure, and Dehydrogenation Reactivity of a Water Soluble o-Iodoxybenzoic Acid Derivative Bearing a Trimethylammonium Group. Org. Lett. 2011, 13, 6488-6491. [CrossRef]

31. Samadi, S.; Orellana, A. A New Route to Phenols: Palladium-Catalyzed Cyclization and Oxidation of $\gamma, \delta$-Unsaturated Ketones. ChemCatChem 2016, 8, 2472-2475. [CrossRef]

32. Zhao, L.; Huang, G.; Guo, B.; Xu, L.; Chen, J.; Cao, W.; Zhao, G.; Wu, X. Diastereo- and Enantioselective Propargylation of Benzofuranones Catalyzed by Pybox-Copper Complex. Org. Lett. 2014, 16, 5584-5587. [CrossRef] [PubMed]

33. Shome, S.; Singh, S.P. Design and synthesis of ruthenium bipyridine catalyst: An approach towards low-cost hydroxylation of arenes and heteroarenes. Tetrahedron Lett. 2017, 58, 3743-3746. [CrossRef]

34. Bayguzina, A.R.; Tarisova, L.I.; Khusnutdinov, R.I. Synthesis of Hydroxybenzoic Acids and Their Esters by Reaction of Phenols with Carbon Tetrachloride and Alcohols in the Presence of Iron Catalysts. Russ. J. Gen. Chem. 2018, 88, 208-215. [CrossRef]

35. Gopinath, R.; Barkakaty, B.; Talukdar, B.; Patel, B.K. Peroxovanadium-Catalyzed Oxidative Esterification of Aldehydes. J. Org. Chem. 2003, 68, 2944-2947. [CrossRef]

36. Brenner, J.E. The Synthesis of 2-Carboethoxy- $\Delta^{2}$-cyclohexenone. J. Org. Chem. 1961, 26, 22-27. [CrossRef]

37. Magano, J.; Chen, M.H.; Clark, J.D.; Nussbaumer, T. 2-(Diethylamino)ethanethiol, a New Reagent for the Odorless Deprotection of Aromatic Methyl Ethers. J. Org. Chem. 2006, 71, 7103-7105. [CrossRef]

38. Parkins, M.V.; Kitching, W.; Drew, R.A.I.; Moore, C.J.; König, W.A. Chemistry of fruit flies: Composition of the male rectal gland secretions of some species of South-East Asian Dacinae. Re-examination of Dacus cucurbitae (melon fly). J. Chem. Soc. Perkin Trans. 1990, 1, 1111-1117. 